\title{
Understanding bereavement experiences of mothers facing the loss of newborn infants
}

Larissa Rodrigues 1

https://orcid.org/0000-0001-8714-7010

Daniela Danttas Lima 2

(iD) https://orcid.org/0000-0001-6712-0240

Juliana Vasconcelos Freitas de Jesus 3

D https://orcid.org/0000-0001-9136-478x

Gabriel Lavorato Neto 4

https://orcid.org/0000-0001-8277-1463

Egberto Ribeiro Turato 5

D https://orcid.org/0000-0002-7857-1482
Claudinei José Gomes Campos 6

iD https://orcid.org/0000-0001-9587-6694

1-5 Faculdade de Ciências Médicas. Universidade Estadual de Campinas. Rua Alexander Fleming, 101. Campinas, SP, Brasil. CEP: 13.083-970. E-mail: rodrigues-larissa@uol.com.br

6 Escola de Enfermagem. Universidade Estadual de Campinas. Campinas, SP, Brasil

\begin{abstract}
Objective: to understand mothers' bereavement experiences regarding the loss of their newborn child in the Neonatal Intensive Care Unit of a Brazilian university hospital.

Methods: the study was designed by the clinical-qualitative method to understand the meaning of the emerging relationships of health scenarios. Sample consisted of six mothers. The sufficiency of the sample was verified through the saturation of the data. The data collection instrument was a semi-structured interview with script of open questions, the collected material was recorded and transcribed in full. Thematic analysis was performed by two independent authors.

Results: feelings and perceptions of the grieving process gave rise to three categories: 1 . Guilt and fantasy of bereavement related to the death and grief for their children; 2. Relationships and ambiguities - the relationship between internal concerns and perception of external relations; 3. Fear, disbelief, abandonment and loneliness - questions about perception of the external environment.

Conclusions: mothers' bereavement experience is mainly permeated by loneliness and abandonment related to feelings of guilt for not being able to keep their children alive. The difficult and definitive separation in the postpartum period, caused by death, brings fantasies of reunion with their child. Women show the need to realize grief, especially by recognizing their baby's identity.
\end{abstract}

Key words Grief, Mothers, Neonatology, Life experience, Medical psychology

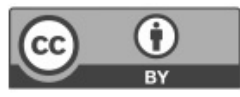




\section{Introduction}

Perinatal mortality is estimated to affect approximately 2.6 million infants per year worldwide. ${ }^{1}$ Each death is accompanied by great sadness and distress, not only by the mothers and their families, ${ }^{2}$ but also for healthcare professionals involved. Each year, approximately 2 million women live with symptoms of postnatal depression due to perinatal loss, ${ }^{3}$ which has associated direct and indirect costs, including medical care and investigation at the time of the death to assess its impact on future pregnancies, funeral expenses, reduced social performance, impacts on relationship and breakdown of the family unit, and negative effects on employment. ${ }^{4-9}$

Literature reviews aimed at evaluating these experiences report the presence of psychological symptoms in mothers, including high rates of depression, anxiety, post-traumatic stress disorder, suicidal ideation, panic and phobias, 9,10 with the onus tied to these emotional demands being intangible. Studying mental health during the postnatal period is critical for designing appropriate assistance, which will aid in the prevention of damages to the bereaved in terms of their well-being and social life.

"There are gaps in perinatal mental healthcare knowledge, which is unacceptable in the area of maternal and child health, this gap must be filled, and these women and their families must be cared for". 11 A lack of studies in this area suggests that perinatal mortality and its consequences for mothers are undervalued. Further, it is clear that communication with mothers who experience the loss of their child should be systematized. 12

Recently, two reviews were published concerning tools highlighted in previous publications for intervention work with parents and family. ${ }^{13,14}$ Indeed, new studies on perinatal grief could aid in increasing our understanding and knowledge of this subject, and thus contribute to improved attentiveness by healthcare professionals for this vulnerable population. Therefore, the current study aimed to understand the meanings attributed to personal experiences of Brazilian mothers who are grieving the death of their child in a Neonatal Intensive Care Unit (NICU).

\section{Methods}

The study design followed the clinical-qualitative method, which is based on three pillars: existentialist attitude that considers anguish and anxiety present in the existence of the participant subject; clinical atti- tude of reception of emotional suffering through listening and looking; and psychoanalytic attitude, using concepts derived from individual unconscious dynamics. 15

The sample was intentional and the following inclusion criteria were considered: age greater than or equal to 18 years; being a mother of a newborn deceased in the NICU of the Center for Integral Attention to Women's Health; and showing emotional and cognitive ability to share their experience. All women invited to the support group meeting for bereaved parents between February and November 2016 met the above criteria. They agreed to participate in the study and signed informed consent.

The group of bereaved parents of the Center for Integral Attention to Women's Health receives parents who have lost a newborn in the NICU. Most parents attend three to 12 months after the death of their newborn. The meetings are held monthly with duration of approximately three hours. During data collection, the interviewees were the only participants attending these meetings.

The interviews took place in a reserved room in the Division of Neonatology of the mentioned university hospital (three cases) and in the domicile of the participants (three cases). A semi-structured interview technique was used, with the following triggering question: "How did you feel after your child's death?"

Demographic data was obtained for each participant. Each interview lasted 60 minutes, and focused on experiences of grief after the death of a newborn child, exploring perceptions about marital and family interactions as well as those in their social environment. The sufficiency of the sample was verified through the theoretical data saturation. 16 The observations made by the first author during data collection were written in a field diary. The written records of this diary were added to the text of the transcribed interviews and made it possible to discuss the inferences about the process.

The process of data analysis was comprised of seven steps provided in the thematic analysis used in the clinical-qualitative method. $15,17,18$ These steps are described below and the initials of the authors involved in each of them are in parentheses:

1. Text editing for transcription of recorded interviews, along with field diary notes. Audio recordings were made with the Super Voice Recorder application. The colloquial speech used by the participants remained in the transcriptions, with correction of the grammar to facilitate the understanding of the content, respecting the individuality of each subject; 
2. Hearing and rereading of transcripts, independently analyzed by two authors. The coding results of the two authors were compared and discussed until a consensus was reached;

3. A record of comments and impressions on this rereading, written in the right margin of the transcribed text;

4. Classification and subclassification to promote the grouping of units of meaning and significant points of discourse in the text for this study;

5. Presentation and discussion of material for peers;

6. Definition of categories as a result of the study of the material and organization of the text;

7. Peer data validation (discussion with other authors involved in this study, supervisors, and members of the research groups in which researchers participate). Presentation of abstracts of this study at two European conferences.

The study went through COREQ Checklist. 19

This study was performed between February and November 2016, following the ethical approval of the University of Campinas, SP, Brazil, under registration number CAAE: 51329215.6.0000.5404 on Feb. 18, 2015.

\section{Results}

Six mothers invited to the meeting of a support group for bereaved parents were interviewed. All had experienced losing a newborn child while hospitalized in the NICU of the same hospital three to 11 months prior to the interview. The sociodemographic characteristics can be observed in Table 1. Feelings and perceptions demonstrated during the mourning process by the participants gave rise to three categories.

The following sections describe the feelings of anguish expressed by the mourners. They form a connection between the death of the newborn and the continuation of the mothers' lives. Further, the themes contain a certain cosmology, a symbolism built up by the bereaved mothers representing the life of their deceased child (the memory of their experience with the deceased and the event of their death as well as the way they imagine their lives if their child was still alive).

\section{Guilt and fantasies of the bereaved related to their child's death and grief}

Guilt is experienced and described in the context of fantasies that originated from the infants' death. Metaphorically, other forms of death are correlated to the experience of the subject, such as a mother who has undergone a tubal ligation procedure for sterilization during birth to her baby who then passes away later. Her guilt comes from having agreed to a procedure that prevents her from ever being a mother again. As one mother explained, she felt tubal ligation reversal might ease her pain of grief:

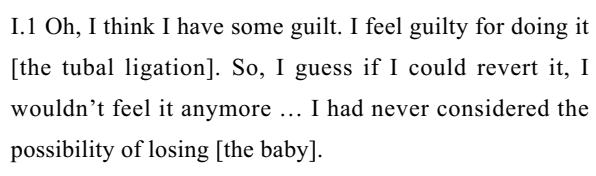

The participants also fantasize about feeling the presence of their deceased child:

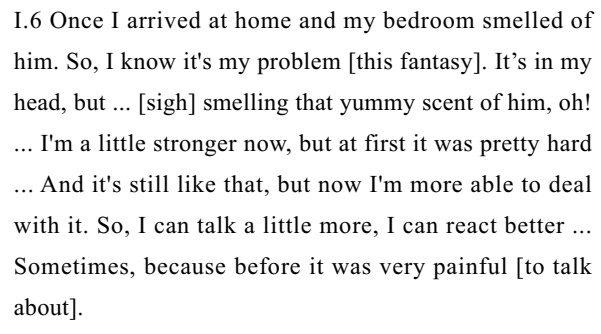

In addition, horrible sensations and perceptions of symptoms that take them by surprise are reported,

Table 1

\begin{tabular}{|c|c|c|c|c|c|c|c|c|c|}
\hline & $\begin{array}{l}\text { Age } \\
\text { (years) }\end{array}$ & Religion & Educational level & $\begin{array}{l}\text { Marital } \\
\text { status }\end{array}$ & $\begin{array}{c}\mathbf{N}^{\circ} \\
\text { pregnancies }\end{array}$ & $\begin{array}{l}\mathrm{N}^{\circ} \text { living } \\
\text { children }\end{array}$ & $\begin{array}{l}\text { Ethnic- } \\
\text { racial } \\
\text { identity }\end{array}$ & $\begin{array}{l}\text { Interview } \\
\text { time }\end{array}$ & $\begin{array}{r}\text { Duration of } \\
\text { grief (months) }\end{array}$ \\
\hline I. 1 & 34 & Evangelical & Middle school & Married & 4 & 2 & White & $1 \mathrm{~h} 17 \mathrm{~m} \mathrm{46s}$ & 3 \\
\hline 1.2 & 25 & Agnostic & Middle school & Married & 4 & 2 & Non-white & $27 \mathrm{~m} \mathrm{25s}$ & 3 \\
\hline 1.3 & 31 & Spiritualist & College degree & Single & 1 & 0 & Non-white & 1h $28 \mathrm{~m} \mathrm{47s}$ & 7 \\
\hline 1.4 & 27 & Catholic & High School & Married & 3 & 2 & White & 1h $28 \mathrm{~m} \mathrm{04s}$ & 7 \\
\hline 1.5 & 26 & Evangelical & Middle school & Married & 6 & 5 & Non-white & $28 \mathrm{~m} \mathrm{05s}$ & 11 \\
\hline 1.6 & 34 & Catholic & Technical Education & Married & 1 & 1 & White & $44 \mathrm{~m} 18 \mathrm{~s}$ & 3 \\
\hline
\end{tabular}


as if they are experiencing their child's death within themselves:

I.3 A week after my baby's death, I had shortness of breath for a week. I woke up every day in the middle of the night with shortness of breath, desperation. Then I said 'Oh, my God!' You know? Then you start to think about a lot of things, 'Wow! Is it because of the baby?' Because before, in the ICU ... his face went purple [and] he had no air! He wasn't breathing. Then I put my hand like this and didn't feel any air. Suddenly he came back, you know? When it seems that someone drowned and then came back, all of a sudden?

Self-destructive thoughts and the understanding of suicidal behavior reveal the hopelessness felt by the bereaved, causing them to attribute negative meanings to life experiences, expressing the desire to be with their child.

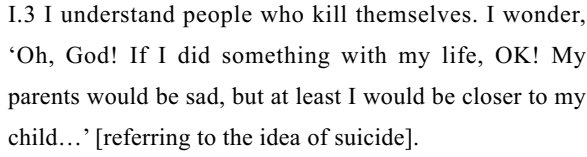

\section{Relationships and their ambiguities - the relation between internal concerns and the perception of external relationships (spousal/family)}

Internal issues cause the bereaved to direct their feelings to the ones closest to them; therefore, relationships with family and friends become saturated by mixed feelings. Unrecognized or unauthorized grief reinforces the suffering of the bereaved. In terms of our participants, they imagine that others will judge them as ungrateful for suffering "only for the one who died" when they have other children needing their attention. This brings further suffering and efforts to justify their pain:

\footnotetext{
I. 2 A lot of people can talk what they want, right? With others I usually say, it's like, 'Oh, but you already have two children!' Even so! I say, 'It could have been 10 children; it would not reduce the pain ...' I miss him.
}

Participants in this study report ambiguity of feelings towards their partner. While the women claim that their male partners also suffered when losing their child, they also point out their lack of pain. This leads to feelings of anger from the mothers since they assume that their husbands are not as affected by their loss and are, therefore, unable to understand their partners suffering and behavior.

Another way to evaluate their experience is concerning the confrontation between them, and presenting the dynamic of the grieving process in intersubjective relationships.

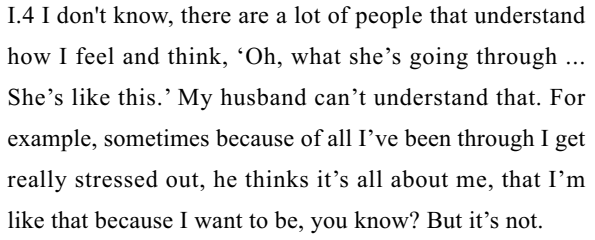

The angst felt with loss leads the mother to think warmly of others, particularly of her partner. Therefore, when her partner does not live up to her expectations, it leads to the accumulation of a new loss and increases her suffering, which is highlighted by the reporting of failure:

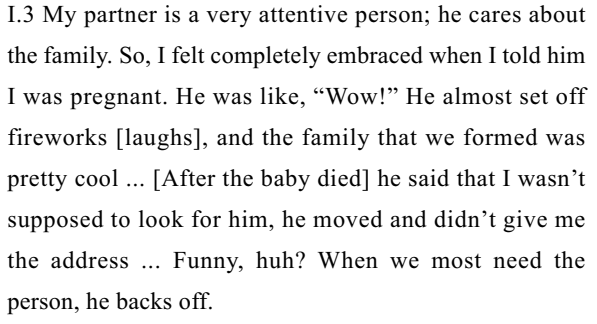

Fear, disbelief, abandonment and loneliness questions about the perception of the external environment (social)

Lastly, feelings related to their social environment include those concerning the behavior necessary for continuation of their activities of daily living. Below, a bereaved mother reflects on the responsibility of becoming pregnant and going through a new loss:

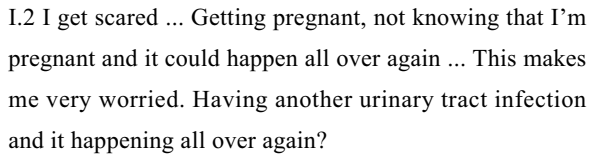

When considering the bereaved, a significant effort is made by the mothers to explain their suffering towards society, to justify the enormity of their pain, including physical symptoms. As the mothers expressed, their babies should have survived, as this is what is expected from a pregnancy.

I.4 A lot of people think that the pain I feel is not real, but my hair is falling out, my nails ... And today, in fact, 
apparently many people forgot [the death]. For example, my mother, my relatives, and my husband's relatives can live normally, without remembering that my son died. They only remember when I say something. But it's hard for me, you know? I don't forget it.

The bereaved mothers perceive their experience in terms of ineffectual support received in healthcare centers.

I.1 [in relation to the tremor felt in her right eye] It's stress [spoke the professional]. I mentioned, when I was pregnant, the eye that was trembling and bothered me, and it bothers me, but it seems that they don't see the woman, they focus on the baby, it seems that they don't care about

The "eye that flickers" is taken as a call for help by the healthcare professional. "Non-specific physical complaints seem to be related to a body that is suffering with grief."

Further, the bereaved mothers expressed the invisibility of the father within healthcare centers:

I.3 What I think is that all institutions are only interested in the mother's side, and forget to listen to the father. He's also suffering, he also needs support.

The participants also demonstrated that working relationships are also affected by the grieving process, which may also affect the economy of the family by causing upset in the daily routine, with the threat that unemployment represents.

\footnotetext{
I.3 My ex-husband is also in a bad situation because he lost his job. Now, recently they said that his productivity fell. So, for the company is like that. While you're producing is great, your problems stay outside. Then he lost the child, they waited a week or so and said, 'Oh, why do you think your productivity fell?' Why is it, huh?
}

Assistance for the bereaved does not foresee the types of support and services necessary. For instance, economic issues were of paramount importance from the perspectives of the participants and, therefore, the formation of an extended support network among healthcare services and the performance of the professionals that work within these institutions were important impact factors for participants in our study.

\section{Discussion}

Giving an identity to the baby and building memories to appreciate their children is a strategy mothers used to cope through the postnatal period. Notably, it was important to notice the binomial mother and child was undone, and to help her to understand that she is alive, even though her baby is deceased. Some mothers also raised doubts regarding future pregnancies and expressed their fear of carrying another child.

The participants of this study also described a lack of social recognition. They reported that even with court records, represented by birth and death certificates, general opinion is that the baby is not recognized, except by heavy individual suffering. The participants of the current study had a relatively short period of contact with their infant children, yet they achieved a nurtured relationship established during the intrauterine stage and the few days of day-to-day life during the baby's hospital stay. Thus, they imagined how their relationship with their baby would have continued, dreaming of the parent-child relationship, among other ideas that give acceptability to suffering.

The guilt felt by wanting to destroy a beloved object, when it brings frustration, is followed by the need to repair this object, this is inherent to the human being from a very young age and is a measure presented by the mothers in relation to the newborn dead, in this perspective, neonatal death places the mourners in a situation of suffering because they lose the possibility of this reparation. 20

The fantasy is considered a structure by which the subject relates to external objects. 20 Fantasy life is therefore "the land where the mind and the individual personality grow." Mourners' fantasies about death and their meanings are poignant during the mourning period, which causes great distress to these mothers. This is clear when they report living these fantasies as concrete, and this issue prevents them from perceiving the potential support present in friends and family. ${ }^{21}$

Prohibiting the period of bereavement compromises the mental health of mothers, and this prohibition postpones the mother's confrontation with the death of the child and the restoration of the activities of daily life. This can remove her from her personal and professional relationships, which may bring economic impacts due to job loss and absenteeism as well as impacts on family relationships and roles. The invisibility of grief brings suffering and solitude. 22 Lack of economic support and assistance during the grieving process were emphasized in the 
discourse of the participants in this study. Thus, the interruption of the employment bond and the problems in relationships with the employers complicated the anguish of bereaved mothers.

In this sense, it is essential to give legitimacy to the existence of the baby and the pain that the loss of this newborn brings to the mother. Supporting and respectful gestures, such as taking pictures and storing clothes and blankets used by the newborn, have been described as important ways of giving identity and constructing baby memories.23,24 Similarly, talking about the child's death benefits these women as they are able to share a real experience.

Participants in this study reported periods of misunderstanding and periods of anger against others, symbolizing anger against the death of the newborn and against their own lives, which has had an impact on self-esteem and self-identity. These periods of anger are interspersed with periods of guilt for realizing that you are capable of having this bad feeling, which denotes an ambiguity of feelings. This ambiguity is also demonstrated in other studies. $25-27$

Practitioners are likely to experience this anger by their close proximity to the bereaved mother, for that event, they should be strengthened and prepared. 28

Mothers believe they will not be able to take responsibility for acts committed when stricken by the anger described. Other studies have also described this sense of loss of control.8,9 Some women, when interviewed in other situations, took this experience to subsequent pregnancies and began to question their effectiveness in the role of mother after watching their newborn die and feeling powerless to keep them alive. 8,9

Because they feel that they have failed in their role as mothers, some women isolate themselves. Mothers in our study referred to the social stigma of having a dead child. Similarly, bereaved women have described avoiding people who have seen them pregnant. 29 One of the participants in this study revealed that she wanted to take her own life, concentrating on the desire to be with her deceased baby. This is similar to the findings of a study that demonstrated how some women wished to remain in the habits of when they were pregnant, as the pregnant body seemed to maintain the mother-child connection. $8,9,30$

Providing theoretical contributions to parental grief, aiding in the understanding of how mothers incorporate their grief experiences in their daily life and how they deal with the expectations of birth and death in a single moment, may generate future research around the themes addressed in this study as well as support professionals in bereavement counseling. This study is limited to a group of individuals in a specific social context and at a particular point in time. Indeed, maternal experiences predominate in the findings of this study, as paternal presence in the support group was lacking. Perhaps future researches might explore the paternal perspective of mourning.

\section{Final considerations}

The experience of mothers who passed through the death of their newborn child in the NICU of a Brazilian university hospital is permeated by feelings of loneliness and abandonment. These women take the blame for feeling unable to keep their child alive and they are afraid of having another child who might die. We understand that the unbearable separation of their child gives rise to fantasies about the child's presence and also to a possibility of reunion with their baby that causes feelings of self-destruction. They attribute the pain they feel to events other than the child's death and this feeling influences behaviors of anger and isolation, unbalancing their relationships.

This study sought to clarify to health professionals about the need for care for bereaved mothers. Understanding bereaved mother's experience can transform clinical management and approach. Health teams can be structured to welcome and counsel these women because it will help in understanding the condition of frailty and their emotional impact. Establishing effective communication with these women can ensure information on the reasons and consequences of all actions taken by the team in relation to the baby and preserve his/her dignity and identity.

\section{Author's contribution}

Rodrigues L conducted the interviews. Campos CJG and Rodrigues L independently analyzed the transcripts of the interviews. Lima DD and Jesus JVF contributed to the design of the study. Rodrigues L, Lima DD, Campos CJG, Jesus JVF and Lavorato Neto G compared and discussed the data until consensus was reached. All authors read and approved the final version of the article. 


\section{References}

1. Mullan Z, Horton R. Bringing stillbirths out of the shadows. Lancet. 2011; 377 (9774): 1291-2.

2. WHO, Every Woman Every Child. The Global Strategy for Women's, Children's and Adolescents' Health (2016-2030): Survive, Thrive, Transform. World Health Organization: New York; 2015. Available on: https://www.who.int/life-course/partners/globalstrategy/globalstrategyreport2016-2030-lowres.pdf

3. Molla M, Mitiku I, Worku A, Yamin AE. Impacts of maternal mortality on living children and families: A qualitative study from Butajira, Ethiopia. Reprod Health.2015; 12 (Suppl. 1): S6.

4. Bazile J, Rigodon J, Berman L, Boulanger VM, Maistrellis E, Kausiwa P, Yamin AE, Intergenerational impacts of maternal mortality: Qualitative findings from rural Malawi. Reprod Health.2015; 12 (Suppl. 1): S1.

5. Bond D, Raynes-Greenow C, Gordon A, Bereaved parents experience of care and follow-up after stillbirth in Sydney hospitals. Aust N Z J ObstetGynaecol. 2018. 58 (2): 185 91

6. Goldstein RD, Lederman RI, Lichtenthal WG, Morris SE, Human M, Elliott AJ, Tobacco D, Angal J, Odendaal H, Kinney HC, Prigerson HG. The Grief of Mothers After the Sudden Unexpected Death of Their Infants. Pediatrics. 2018; 141 (5): e20173651.

7. Knight L, Yamin AE. "Without a mother": caregivers and community members' views about the impacts of maternal mortality on families in KwaZulu-Natal, South Africa. Reprod Health.2015; 12 (Suppl. 1): S5.

8. Pande RP, Ogwang S, Karuga R, Rajan R, Kes A Odhiambo FO, Laserson K, Schaffer K. Continuing with "...a heavy heart"- consequences of maternal death in rural Kenya. Reprod Health.2015;12 (Suppl. 1): S2

9. Kavanaugh, K.; Hershberger, P., Perinatal loss in lowincome African American parents. J Obstet Gynecol Neonatal Nurs. 2005; 34 (5): 595-605.

10. Lee C. 'She was a person, she was here': The experience of late pregnancy loss in Australia. J Reprod Infant Psychol.2012;30 (1): 62-76.

11. Lancet $\mathrm{T}$. Research matters: challenges of replication. Lancet. 2017; 389 (10072): 882.

12. Gold KJ, Treadwell MC, Mieras ME, Laventhal NT. Who tells a mother her baby has died? Communication and staff presence during stillbirth delivery and early infant death. J Perinatol. 2017; 37 (12): 1330-4

13. Huberty JL, Matthews J, Leiferman J, Hermer J, Cacciatore J. When a Baby Dies: A Systematic Review of Experimental Interventions for Women After Stillbirth. Reprod Sci. 2017; 24 (7): 967-75.

14. Lari Rodrigues L, Shimo AKK, Carmona EV, De Moraes MHBL, Campos CJG. Suporte aos pais que vivenciam a perda do filho neonato: revisão de literatura. Aquichan.[Online] 2018; 18 (1): 80-94.
15. Turato, E., Treaty of clinical qualitative research methodology: Theoretical epistemological comparative discussion and application in the áreas of health and human Science. 5 ed. Petrópolis; 2013.

16. Fontanella BJ, Ricas J, Turato ER. Saturation sampling in qualitative research: theoretical contributions. Cad Saúde Pública. 2008; 24(1):17-27.

17. Faria-Schutzer DB, Surita FG, Alves VL, Vieira CM, Turato ER. Emotional Experiences of Obese Women with Adequate Gestational Weight Variation: A Qualitative Study. PLoS One. 2015; 10 (11): e0141879.

18. Faria-Schutzer DB, Surita FGC, Alves VLP, Bastos RA, Campos CJG, Turato ER.Seven steps for qualitative treatment in health research: The Clinical-Qualitative Content Analysis. Ciên Saúde Coletiva. [Online] 2019. Disponível em: http://www.cienciaesaudecoletiva.com.br/artigos/ seven-steps-for-qualitative-treatment-in-health-researchthe-clinicalqualitative-content-analysis/17198? $\mathrm{id}=17198$

19. Tong A, Sainsbury P, Craig J. Consolidated criteria for reporting qualitative research (COREQ): a 32-item checklist for interviews and focus groups. Int J Qual Health Care. 2007; 19 (6): 349-57.

20. Klein M. Sobre a observação do comportamento dos bebês. In: Os progressos da psicanálise. Klein M (org.). 4 ed. Rio de Janeiro: Zahar; 1986

21. Leader D. Fantasia em Klein e Lacan. In:Diálogos KleinLacan. São Paulo:Lettera V;2001.

22. Sisay MM, Yirgu R, Gobezayehu AG, Sibley LM. A Qualitative Study of Attitudes and Values Surrounding Stillbirth and Neonatal Mortality Among Grandmothers, Mothers, and Unmarried Girls in Rural Amhara and Oromiya Regions, Ethiopia: Unheard Souls in the Backyard. J Midwifery Womens Health. 2014; 59 (Supl. 1): S110-7.

23. Shelkowitz E, Vessella SL, O'Reilly P, Tucker R, Lechner BE. Counseling for personal care optionsat neonatal end of life: a quantitative and qualitative parent survey. BMC PalliatCare. 2015; 14: 70.

24. Flenady V, Boyle F, Koopmans L, Wilson T, Stones W, Cacciatore J. Meeting the needs of parents after a stillbirth or neonatal death. BJOG. 2014;121 (Suppl. 4): 137-40.

25. McCreight BS. A grief ignored: narratives of pregnancy loss from a male perspective. Sociol Health Illn.2004; 26 (3): 326-50.

26. Saflund K, Sjogren B, Wredling R. The role of caregivers after a stillbirth: views and experiences of parents. Birth. 2004; 31 (2): 132-7.

27. St John A, Cooke M, Goopy S. Shrouds of silence: three women's stories of prenatal loss. Aust J Adv Nurs. 2006; 23 (3): 8-12.

28. Rosenbaum J, Smith J, Zollfrank R. Neonatal End-of-Life Spiritual SupportCare. J Perinatal Neonat Nursing. 2011; 25 (1): 61-9. 
29. Murphy S. Reclaiming a moral identity: stillbirth, stigma and 'moral mothers'. Midwifery.2012; 28 (4): 476-80.

30. Fottrell E, KL Goufodji S, Bèhague DP, Marshall T, Patel $\mathrm{V}$, Filippi V. Risk of psychological distress following severe obstetric complications in Benin: the role of economics, physical health and spousal abuse.Br J Psychiatr.2010;196 (1): $18-25$.

Received on December 10, 2018

Final version presented on September 16, 2019

Approved on December 23, 2019 